\title{
Data Management, the Pathway to Nigerian Development
}

\author{
Odebola Taiwo James \\ Department of Economics, Near East University, Lefkosa, North Cyprus
}

\section{Email address:}

tjodebola@yahoo.com

\section{To cite this article:}

Odebola Taiwo James. Data Management, the Pathway to Nigerian Development. Science Research. Vol. 9, No. 4, 2021 , pp. 69-74. doi: $10.11648 /$ j.sr.20210904.15

Received: November 20, 2020; Accepted: January 21, 2021; Published: August 24, 2021

\begin{abstract}
A juxtaposition on Knowledge Economy as it relates to Nigerian economic condition where there is need to fully approach data-intensive innovations and programs in the attendant condition as it is germane to engender increased goods and services via production to an expanded GDP, economic growth cum development. An economic paradigm needed for the welfare of the citizenry, more importantly, for equitable distribution of resources as in resonance with Development Economics cum Knowledge Economy as branches of Economics that can transform an economy positively from a position of inadequate structures to a level of maximum capacity utilization, that is why this work seek to test if there is any significant relationship between data management and economic development in the selected economies by translating to increase in aggregate demand, investment and reduction in unemployment rate precisely in the developed or OECD economies relative to Nigeria as the economy in perspective. The work theoretically attempted to use Gross Domestic Product, GDP as the exogenous variable which is being impacted by data management as the endogenous variable using Ordinary Least Square, OLS methodology to evaluate if any correlating or significant relationship exist between GDP of an economy and information management in the face of feasible data policy. Therefore, this work posited that Data collection, management and storage with requisite policy in place can help the Nigerian economy achieve its full economic potential, capacity building and capacity utilization.
\end{abstract}

Keywords: Economic Importance of Data Management, Data Policy and Economic Implications,

Feasible Data Policy in Nigeria, Data Management and Nigerian Growth,

Information Technology's Impact on Economies, Database Technology in Economic Development, Information Management and Nigerian Stability

\section{Introduction}

Information is said to be vital to the successful existence of human kind, therefore an environment, economy or personality void of information is actually not living, we learn every day and we fill our minds with information either consciously or unconsciously. We must also seek to feed our heart with necessary knowledge that helps it to develop and to give feedbacks to our being and the environment, same as applicable to nations and organizations as what is obtainable in knowledge economy. Data gathering is all-encompassing, it takes into cognizance every aspect of human life and existence cum endeavours. Data availability plays a major role in the development of an economy, it is feasible and evident that most countries which fall in the leagues of developed nations are data-rich, data-enabled and intensive [15]. That is not only the case, these leagues of nations have adequate and accessible data bank and storage which ensure all citizens and residents are well captured and represented in the nation's information pool, even as obtainable in the EU [7]. They ensure profiling of the citizenry and residents have an outlook that can be easily pooled for instances ranging from welfare, to personal, governmental, financial, security, crime and health purposes. The above benefits and the need for their appropriation to help both the state and the individual were what prompted and culminated into the creation of Data Protection Day slated for January $28^{\text {th }}$ to earmark a day in a year to emphasize the need for data protection [13] as the state, organizations and online platforms or providers process data inputted in their receptacle or portal by prioritizing privacy cum interests of givers and users of information [7]. The proof beyond doubt exists that no economy approaches growth and development status or template without adequate data capturing, management and storage. Therefore, Nigeria as a nation must 
intensify its data policy as touching adequate and efficient profiling cum storage of information of its citizenry and polity [17].

\subsection{Research Objectives}

Information is key, we do not only need to store information about people, we actually need data on every aspect of an economy ranging from the citizens, to properties, history, financial transactions, national income accounting, expenditure or budgeting. Therefore the objectives of this work relative to the Nigerian economy are as stated:

1. To showcase the importance of data profiling, pooling, management and storage to an economy, particularly Nigeria and other Less Developed Countries, LDCs.

2. To enunciate ways by which proper and adequate information can be garnered and generated.

3. To highlight economic benefits and importance of information capturing and data management.

\subsection{Theoretical Framework/Questions}

Looking at some countries with large and teeming population, and some who have translated their massive population to a growth enabling factor considering nations like America and China with effective data management and are data-driven, some unanswered questions still come to mind, and they are:

1. Is data gathering and profiling actually a step to economic development.

2. Is it actually possible to capture and have all data or necessary information which are germane captured or profiled in the prevailing condition in an economy?

3. Is data availability a possibility to positive transformation of a nation or an economy?

\section{Literature Review}

There are existing literature and works on the importance of data gathering and processing, therefore this work is pivoted on past works and studies on information management and how it engenders growth cum development in economies, organizations and several public or corporate embankments. Maryam et al., stipulated in their study about 'the use of ICT and its effect on economic growth' in 159 countries over the period of 10 years spanning 2000 to 2009 that it has positive implication of transforming to economic growth, and the development from ICT use is more feasible and effective in advanced countries [10]. Khan et al., from their work on how digitization of information and data can impact the economy submitted that digitalization of data for public use is cost effective and has positive effect on the overall economy by reducing unemployment, increasing efficiency and availability of resources both in private and public sectors [16]. Ayoub Yousefi, examined contributions of labour, ICT and non-ICT capital by using a cross-country time series data evaluation for period 2000-2006 for 56 countries across developed and developing nations with conclusion that ICT has visible impact in high and uppermiddle income nation states compared to less developed economies, stating that the minimal effect in low income countries is not as result of poor investments in ICT but poor policy [1]. Kheng and Kelly, on 'the effect of ICT on world economic growth' juxtapose that the effect of ICT on nations is a function of the geographical landscape and existing structures, more importantly that policies have to be finetuned to enhance investments in ICT which can effect global economic growth tremendously [8]. More so, OECD research project in 2014 on knowledge-based-capital (KBC), concluded that data-driven innovation is contributory to economic growth both in the private and public sectors [12]. Also Joseph Kennedy's work titled "Big data's economic impact" buttress the fact that large data management is key, in that it increases economic activities, profits of firms and standard of living, however, it states that challenges such as that of privacy, analytics and free flow of data can affect demand, supply, markets or economies of scale [6]. Succinctly, the European Union funded project on "the economic benefits of open data", posited on the impact of open data at micro and macroeconomic levels in an assessment conducted spanning Europe that accessible data enhances decision making, transparency, government effectiveness and accountability with increase in quality of life and products [3]. In actual fact, Rachel Wheeler categorically submitted that Nigeria is a nation facing a lot of structural inadequacy, but an effective venture in data gathering and processing can help the economy achieve growth that can place the country economically in tandem with other high income countries, same applies to many LDCs peradventure they analyze data about their polity thereby addressing problem imminent in their economies and affecting their developments [14]. However, in the recent work of Dan Ciuriak, which enunciates that data transformation in societies is posing serious socio-economic risks and challenges, except the fact remains that economic policies need be instituted and regulatory frameworks set up for proper management to harness the benefits imminent in data processing [2]. Mike Mandel, on 'Economic impact of data; why data is not like oil' stipulates that data cannot be compared to oil from the saying that 'data is the new oil' because data is not scarce, non-rivaled and cannot be monopolized [11]. Kundishora, hence posits that governments need to be e-literate to monitor or implement enabling policy in ICT sector as it is key to growth [9]. Ysmail submitted that ICT has been the vehicle of economic changes for decades but there is need to increase its Total Factor Productivity, TFP to maintain sustainable economic competitiveness even in OECD nations [18]. These are evident and available researches cum studies juxtaposing the effect of data-driven innovations cutting across different strata of economies globally with attendant challenges and the need for appropriate policy framework to harness growth feasible from data management. 


\section{Impact of Data Availability, Storage and Management}

The way to all round development in Nigeria is to have a data bank capturing every individual, systems and structures in Nigeria. If the LDCs actually know the core importance of data capturing every administration, organization, individual or the government will not downplay the exercise. It has advantages for all sectors of an economy. Nigeria which is classified as emerging market economy and falls in the category of lower-middle income league of nations need to fully approach this program. All high-income, advanced and developed nations have an effective data pool with issued card and identification number, the effective capturing of their citizens' data and biometrics from birth, most issue the identity card at 18 years of age. Although, the Nigerian government in conjunction with NIMC, National Identification Management Centre have kick-started the initiative implementing collection of data but there is need to be more effective with it, that as it is. No country will develop without proper data warehouse, no economy will stabilize without proper data collection or processing, no nation will have maximum security with improper data repository, no country will fight crime and corruption to zero level void of data assembly. In Nigeria, prior to year 2003, apart from government issued identification agencies' form of identifications like driver's license, international passport, voter's card which had information and metrics of selected citizenry, nevertheless, they were not harmonized, but biodata collection actually started from telecommunication companies where you have to register your name for SIM card purchase. It was surprises in mid-2000s when you make calls to providers' customer service agents and they will be telling you the name and the type of phone you are using. Those are benefits of proper data collection. Though, the NIMC and government are engaging private data collectors in the exercise but there is a need for the data to be harmonized to prevent double counting. There should be centres in every hospital capturing new born baby's information and biometrics, maybe at the stage of first postnatal appointment if not at birth. It is easier to monitor and capture the newly-born at public or state-owned hospitals but those from the private health centres may jeopardize the exercise due to improper monitoring. Therefore, new-born babies delivered at private hospitals must be ensured to go and register and get the babies' biometrics captured. More so, at birth registration with state agencies, either from private or public hospital is necessary, it must be ensured the infant's data is properly documented. Capturing their data from birth will make it easier for the program, administering agency and government, particularly for purpose of appropriation as regards census, economic planning cum state records [17]. Nigerian government need to know this and work towards having a central data centre. Just like Rachel Wheeler, a US based blogger has stated in her article, particularly about Nigeria and other less developed countries (LDCs), that Nigeria and other developing nations can accelerate their commerce and enhance their economic potential by engaging in feasible data analysis of the private and public sectors, positing specifically that Nigeria has some structural problems that can be alleviated by embracing data-driven innovations [14]. The effort of the banking sector is commendable with the introduction of Bank Verification Number, BVN, by the Central Bank of Nigeria, CBN but not everybody keeps money in the bank, and also INEC with introduction of Permanent Voters Card, PVC, but not everybody above 18 years are interested in voting. More so, Nigerian Immigration Service, NIS is trying but not everybody wants to travel or own an international passport. Some people were registering for BVN free, while those outside Nigeria paid N20,000 (U\$50) approximately for BVN registration, when the Apex bank's directives ensured commercial banks threatened to block respective accounts of registration defaulters. Those in diaspora thought the central bank and commercial banks will not be effective with their deadline, but at the slated date in October/November, 2015 when accounts of people in diaspora were restricted, they all rushed to do their BVN, so many people traveled to far places within their different countries of residences to register for BVN, same as those in Europe and other parts of the world at designated centres, most of which were situated in Nigerian embassy or consulate abroad for BVN registration and it was actually paid for. Even in Nigeria presently, which is several years after the mandatory registration for $\mathrm{BVN}$, people are in banks everyday still coming for BVN registration, this shows BVN is effective but not all-encompassing, so is PVC, International passport and the National ID card from NIMC. The solution lies with NIMC as the agency designated with data collection, and the engagement of private data collectors just as it is obtainable, but there is need for proper harmonization. The police cannot take finger prints from crime scene, what will they do with the finger prints and which data receptacle will they pool the suspects profile from? But it is more or less possible now with PVC, BVN, NIMC and Nigerian immigration service data bank. Succinctly, in respect of security and in a crime case, a suspect may not be a voter, a traveler or an account holder. More importantly, are Nigerian police accessible to this data warehouse? What about our Nigerian Army and Force combating Boko Haram every day in the northeastern region where the activities of the Boko Haram terrorists are fully in attendance, a feasible data system can improve this situation and help the function and duties of these security personnel facing crime and insurgency operations. From what is obtainable globally in the economic and international scene, all the nations from the lists of countries in EU, G-7, G-8, OECD, and G-20, all of them have effective data repository for their citizens even from birth [15], whereas countries from less developed nations, LDCs, most of them do not have effective data capturing or management, about few with effective but mostly not from birth and some of them only with government agencies which take finger prints or biometrics, though most with viable data structures are found in Northern and few from Southern Africa, however, 
there are some few countries in the Asian region still lacking in this important exercise. Maryam et al, posited in their work that the use of ICT on economic growth is germane by examining 159 nations over 10 years spanning 2000 to 2009 stating that it prompted and translated to economic growth, and the development is more in high income countries, [10] this indicate that the efficiency in data management in a prevailing economic condition requires economic policies to be adequately appropriated, which shows that poor policy and polity may affect the effectiveness of data regulation even in positive transformation of an economy same as the postulation of Yousefi, for achieving commercial expansion and full economic potential, even for member nations belonging to Organization for Economic Cooperation And Development, OECD [1].

The importance of effective data profiling and storehouse.

1. To fight crime;

2. To combat Corruption;

3. Equitable distribution of resources;

4. Prevent rigging in elections; In 2011, after the general elections in Nigeria, elections tribunal were battling with rigging issues and they had to employ the services of foreign forensic experts. The only success achieved by the forensic experts was to find solution to election rigging thereby helping tribunal come to election-case conclusion by discovering that some ballot papers and lots of election ballot papers were actually handled by just one person and this helped, but with efficient data receptacle, the security forces will be able to pool the profile of the finger print and just go to pick culprit while he is in his house sleeping or eating from money made from electioneering and racketeering.

5. Security, financial and banking regulations; with proper data repository, it will be easy for creditors, microfinance banks or commercial banks to lend money. Australia and Canada put financial records in each individual's personal profile and it is reflective against their names, ID number and on cards. If you have previous payment default, no bank will give you loan, but if your record is clean, you can get any loan at any time, if you have stolen, your criminal record is put in your profile outlook, same as sex offenders, rapists, child-abusers, molesters and robbers. This is the more reason why crime and corruption is at zero level in high income nations. The wonder that for most of terrorist events in the UK and France only takes few days to apprehend or discover suspects, it is due to the advantage of data storehouse. Advertently, it is necessary in Nigeria that for those who have ever been convicted of a crime, it must reflect in their profile outlook. This helps for easy and proper monitoring cum regulation, and in the long run it translates to economic stability and development. It will help policing, banking, judiciary, regulatory and security agencies or personnel function efficiently. More importantly, there should be an effective accessibility for security agencies, banks, and private institutions even if it is at a cost and to be password-locked and this would be handled by an office in the NIMC structure or government regulated authority. If the private and public administrative agencies in Nigeria and other lowincome nations or from LDCs can embrace viable datadriven innovations and policies in their prevalent economic conditions, there will be feasible growth and development [14] which will make them run their economies efficiently at full capacity, advertently in the long run achieving maximum potential economically from available resources.

\section{Introduction to Research Methodology}

This study is about the economic effects of data management on the national income and GDP of Nigeria, and various data, figures and study would be put to use, more importantly, is the fact that these data would be analyzed to have a concrete conclusion as touching the study scientifically in a manner that follows theoretical and academic study cum research method or plan. Therefore, this chapter will be examining the study cum research design, method of collecting data, samples, variables and justification of the variables used, the intended or proposed data analysis, and the tests to be used as inference. The implication of this work is to evaluate the consequences of data regulation on real output, GDP and national income of Nigeria. The work will show how data processing has instigated increase in investment, aggregate demand and output alongside reduction in unemployment cum inflation relatively with countries who have feasible data repository examining their GDP which will span 1998 to the year 2018.

\subsection{Research Methodology}

This work seeks to showcase its result by using data from different nations who have been known to run an economy with proficient and efficient data system with attendant development present within their economic structures which is common in high-income cum developed economies and typical with super-power economies. Therefore I intend to gather data of countries in the upper income countries using their GDP and real GDP relative to countries in the low and lower-middle income countries, as Nigeria particularly falls in the developing and lower-middle income group of nations or League of Nations. This study will rely on existing and secondary source of data collection and employ ordinary least square (OLS) to analyze the data. The dependent variable is the economic growth to be represented by real GDP or national income while the independent variable is data management.

\subsection{Theoretical Model}

The theoretical model for the study will be taking the form of the below illustration; Stating that National income is a function of efficient data system. The statement of problem and equation will take the form, 


$$
\mathrm{Y}=\mathrm{f}(\text { data })
$$

Where $\mathrm{Y}$ is endogenous variable in GDP or National income denoting development and growth while data is independent variable which represents data gathering, processing and storage.

$$
Y=f\left(a_{1}\right)=f\left(b_{2}\right)=f\left(c_{3}\right)=f\left(d_{4}\right) \ldots f\left(z_{n}\right)
$$

Where $a_{1}, b_{2}, c_{3}, d_{4} . . z_{n}$ represent nations with efficient data system and visible economic growth.

\subsection{Statement of Problem}

This work seek to test if there is any significant relationship between data management and how it has geared economic development in the selected economies by increase in aggregate demand, investment precisely in the developed or OECD economies and reduction in unemployment rate relative to Nigeria as an economy. Therefore, the statement of problem for this study will be

GDP/Output/National Income $=f($ data management $)$

$$
\operatorname{GDP}(\mathrm{Y})=f(\mathrm{~d})
$$

Where GDP $=$ Output or National Income, $\mathrm{d}=$ data management. From this model, data (d) would be the main exogenous, explanatory or independent variable while GDP (Income) would be the endogenous, explained or dependent variable. The dependent variable is the high-income countries' economic growth represented by their respective real GDPs. This is to actually show if there is a direct relationship between data management as one of the parameter that determine increase in output in their economies, and whether national income can be affected by feasible data receptacle and management, particularly, economic development cum stability relative to Nigerian economy. This work is to portray if there exist direct proportional relationship between information management as to increase in investment, income and aggregate demand, with decrease in unemployment if Nigeria as a nation need to embrace the policy.

\subsection{Hypothesis Testing}

This study intends to use Ordinary Least Square, OLS methodology and significant hypothesis tests comparing the levels of development in the leagues of nations belonging to categories of developed, high income, OECD with adequate data profiling relative to nations in the group of developing, LDCs and low income or lower-middle income countries with inadequate data system to posit proper data management can translate or contributory to economic growth, increase in GDP or national income.

Null hypothesis $\mathrm{H}_{0}$ : GDP $(\mathrm{Y}) \approx \mathrm{d}$

Alternative Hypothesis $\mathrm{H}_{1}$ : GDP(Y) $\neq \mathrm{d}$

$H_{0}: Y=\beta_{0}+\beta_{1} X_{1}+\beta_{2} X_{2}+\beta_{3} X_{3} \ldots \beta_{n} X_{n}+\varepsilon$

$H_{1}: Y \neq \beta_{0}+\beta_{1} X_{1}+\beta_{2} X_{2}+\beta_{3} X_{3} \ldots \beta_{n} X_{n}+\varepsilon$

The F-test is at 0.05 as the level of significance that is $5 \%$; therefore the alpha value is $\alpha=0.05$ at $5 \%$ significance level in a two-tailed distribution using the anova (analysis of variance) with tables for results.

The hypothesis equation is a multi-variable case where $\beta_{1}$, $\beta_{2}, \beta_{3}, \beta_{4} . . \beta_{\mathrm{n}}$ are data-driven nations. As in the

Model Specification: $Y=\beta_{0}+\beta_{1} X_{1}+\beta_{2} X_{2}+\beta_{3} X_{3}$ $+\beta_{4} X_{4}+\beta_{5} X_{5 \ldots} \beta_{n} X_{n}+\varepsilon_{1}$

To test the overall significance of the regression equation, the null and alternative hypotheses are also as follow.

Null Hypothesis: $H_{0}: \beta_{1}=\beta_{2}=\beta_{3}=\beta_{4}=\beta_{5} \ldots \beta_{\mathrm{n}}=0$

Alternative Hypothesis: $H_{1}: \beta_{1} \neq \beta_{2} \neq \beta_{3} \neq \beta_{4} \neq \beta_{5} \ldots \beta_{n} \neq 0$

$$
Y=\beta_{0}+\beta_{1} X_{1}+\beta_{2} X_{2}+\beta_{3} X_{3}+\beta_{4} X_{4} \ldots \beta_{n} X_{n}+\varepsilon_{1}
$$

$\mathrm{H}_{0}: \beta_{1}=0$ or $\beta_{2}=0$ or $\beta_{3}=0$ or $\beta_{4}=0 \ldots \beta_{\mathrm{n}}=0$ (all variables are equal to 0 )

$\mathrm{H}_{1}: \beta_{1} \neq 0$ or $\beta_{2} \neq 0$ or $\beta_{3} \neq 0$ or $\beta_{4} \neq 0 \ldots \beta_{\mathrm{n}} \neq 0$ (At least one variable is not equal to 0 )

Where $\mathrm{Y}$ is the National Income (Output/GDP), $\mathrm{d}$ is data efficiency, and $\beta=$ Co-efficients, $X_{n}=$ nations, $n=$ no. of countries sampled, with their respective GDP for period spanning 1998 to 2018 and $\varepsilon$ is the possible error term. More importantly, is that the work would be using a two-tailed anova, OLS regression for data analysis at $\alpha=0.05 \%$ and $95 \%$ significance level with consideration of the F-test and Ttest results and values from the regression analysis to make conclusive decision theoretically. As the T-Test would determine the overall significance of the equation cum variables, while the F-Test for the significance of the samples taken and their values, and to determine the P-values for the significance of the co-efficients. It is expected that the level of data efficiency proxy by (d), is expected to be related to economic growth proxy by GDP/National income (Y) from the analysis and hypothesis test.

\section{Implication of Study}

This study seeks to pinpoint and enunciate the important factors imminent in the fact that an efficient data policy and generation can have on an economy and how that have been used as a template to an efficient administration of nations as evident in developed cum first-world countries. This study will engender scholars, government institutions and the academics to further future studies and policies on proper cum adequate data acquisition, management and regulation, which are important to economic transformation and growth, particularly data policies needed to provide framework for implementation.

Contribution to knowledge and Society

One of the purposes of this work is to reach out to existing knowledge on data management. It is known that many social media, organizations and companies reviewed their data policy in early 2018 [13], particularly which actually emanated from Europe, it was supposedly for data protection and privacy policy [4], that is to say how important data is to the global village, society and our being. Hence the reason why data should be well documented to reflect important, daily and economic activities which must be well processed, managed and stored. More importantly, Nigeria as a nation needs a viable data analytics and 
storehouse which accommodates necessary information that is germane to translating to economic growth in the prevailing condition attendant in the nation's economy, same as other LDCs yet to approach the program.

This work is also targeted at reaching the desk of administrative offices, regulatory and security agencies in Nigeria in respect of the need for a proper data capturing, management, processing and storage sequel to the purpose of attainment of growth and development in the nation.

\section{Conclusion}

The fact remains that for the nation Nigeria to achieve a remarkable developmental status, the case of data availability and policy enablement is key to the economic structures [5], as it is pertinent for the nation to take up this approach which has already started to a point where it will fully translate to a viable growth in the economy of the nation Nigeria. More so, all factors examined so far from existing researches same as this work with all the data to be evaluated and processed will support the fact that appropriate data management and availability will have effective cum advantageous impact on the Nigerian economy as reflective in the globally renowned data-intensive economies who have fully approached the policy. More importantly, from the theoretical perspective and the hypothesis testing, it is evident that data driven innovations (d) and policies would engender increase in output (GDP) and income (Y). This shows that data efficiency (d) is significantly proportional to an expanded output (GDP) and increase in National Income (Y) as expected to be obtained in Nigeria.

\section{References}

[1] Ayoub Yousefi. (2011). The impact of Information and Communication Technology on Economic Growth. Evidence from Developed and Developing Countries. ResearchGate. Doi: 10.1080/10438599.2010.544470.

[2] Dan Ciuriak. (2018). The Economics of Data: Implications for the Data-driven Economy. March 5, 2018. Retrieved from https://www.cigionline.org/articles/economics-dataimplications-data-driven-economy

[3] European Data Portal. (2017). The economic benefits of Open Data. 06 December 2017. Retrieved from https://www.europeandataportal.eu/en/highlights/economicbenefits-open-data

[4] EU Data Protection Rules. 24 July, 2019. European Commission. European Union. Retrieved from https://ec.europa.eu/info/law/law-topic/data-protection/eudata-protection-rules_en

[5] Hunton Andrew Kurth. April 5, 2019). Nigeria Issues New Data Protection Regulation. Privacy \& Information Security Law Blog. Global Privacy and Cybersecurity Law Updates and Analysis. From https://www.hutonprivacyblog.com/2019/04/05/nigeria-issuesnew-data-protection-regulation.
[6] Joseph Kennedy. (n.d) Big Data's Economic Impact. The Committee for Economic Development (CED). Retrieved from https://www.ced.org/blog/entry/big-datas-economicimpact

[7] Janet I. Cord (March 4, 2018), Ladas \& Parry, January 2018 Commission Guidance on the General Data Protection Regulation, European Union, Law Business Research, Lexology retrieved from https://www.lexology.com/library/detail.aspx?g=h4cb694c1df2c-4d05-a667-6f796f4fd23f

[8] Kheng Soon \& Kelly Wee. (2012). Effect of ICT on World Economic Growth (Jan. 5, 2012). Available at SSRN: https://ssrn.com/abstract=1980427 http://dx.doi.org/10.2139/ssrn.1980427

[9] Kundishora SM. (n.d). The Role of Information and Communication Technology (ICT) in Enhancing Local Economic Development and Poverty Reduction. Retrieved from https://siteresources.worldbank.org/CMUDLP/Resources/Role ICT_paper.pdf

[10] Maryam Farhadi, Rahman Ismail, Masood Fooladi. (2012). Information and Communication Technology use and Economic Growth. Public Library of License, PLoS ONE. Doi: 10.1371/journal.pone.0048903.

[11] Michael Mandel. (2017) The Economic Impact of Data: Why Data Is Not Like Oil. JULY 2017. Retrieved from https://www.oecd.org/sti/inno/data-driven-innovation-interimsynthesis.pdf

[12] OECD (2014). Data-driven Innovation for Growth and Wellbeing. October 2014. Interim Synthesis Report. Retrieved from/; https://www.oecd.org/sti/inno/data-driven-innovationinterim-synthesis.pdf

[13] Privacy international, (28 $8^{\text {th }}$ January, 2018): Data Protection Day 2018, A Global Perspective to Privacy. Retrieved from https://privacyinternational.org/news-analysis/1080/dataprotection-day-2018-global-perspective-privacy

[14] Rachel Wheeler. (October 2, 2013). Data Analysis Leads to Economic Growth in Developing Nations. Retrieved from https://www.edq.com/blog/data-analysis-leads-to-economicgrowth-in-developing-nations/

[15] Richards Heeks. (2010). Do Information and Communication Technologies Contribute To Economic Growth, Journal of International Development, 22 (5), 625-640, October 2010, doi: 10.1002/jid.1716. Source RePEc.

[16] Saima Khan, Shazia Khan and Mohsina Aftab. (2015). Digitization and its Impact on Economy. Journal of Digital Library Services. ISSN: 2250-1142 (online), ISSN: 2349302X (print).

[17] World Wide Web Foundation: Personal Data Protection in Nigeria (March, 2018), webfoundation.org, retrieved from http://webfoundation.org/docs/2018/03/WF_Nigeria_FullReport_Screen_AW.pdf

[18] Ysmail Seki. (2008). The Importance of ICT for the Knowledge Economy: A Total Factor Productivity Analysis for Selected OECD Countries. Ideas RePEc. Handle: RePEc: izm: prcdng: 200804. Retrieved from https://ideas.repec.org/h/izm/prcdng/200804.html 